\title{
10 ORGANIZATIONAL DISCOURSE AS A SOCIAL DEFENSE: TAMING THE TIGER OF ELECTRONIC GOVERNMENT
}

\author{
David G. Wastell \\ Information Systems Institute \\ Salford University \\ Manchester \\ United Kingdom
}

\begin{abstract}
This paper focuses on the role of discourse as a means of conferring identity and reducing task-related anxiety. Seeing discourse in this essentially defensive light leads to a new perspective on resistance to organizational change, portraying it as a threat to the defense structure of established discourses. To illustrate, the nascent discourse of electronic government will be examined. Although a potent new discourse, e-government clashes strongly with the discursively embedded social defense systems of local government. A case study is reported in a UK local authority. Drawing on actor network theory, it is shown how the hegemonic influence of the social defenses translated the radical rhetoric of e-government into an operational discourse that was bland and unthreatening.
\end{abstract}

\section{INTRODUCTION: ORGANIZATIONAL DISCOURSE AS A SOCIAL DEFENSE}

The study of organizational discourse is gaining increasing popularity as a way of analyzing the structure and dynamics of complex organizational phenomena. In this paper, the issue of organizational change is addressed from a discourse perspective. The inherently defensive nature of discourse as a social process will be highlighted, arguing that this provides an insightful way of conceptualizing and understanding resistance to change. The paper begins by theorizing the nature of discourse and the role it plays as a defense mechanism.

The original version of this chapter was revised: The copyright line was incorrect. This has been corrected. The Erratum to this chapter is available at DOI: 10.1007/978-0-387-35634-1_28 
The nature of organizational change is then considered, drawing on actor network theory (Latour, 1987) to conceptualize the operation of discourse in effecting a new organizational order. The paper moves on to consider the nature of a powerful new discourse, namely that of e-government, highlighting how it threatens the established social order and entrenched discourses of local government in the UK. A case study of actual e-government discourse will then be reported, in an attempt to understand how the social defenses of one local authority (LA) have substantially withstood and deflected the threat posed by the new discourse.

Many have bemoaned the fuzziness of organizational discourse as a concept, with numerous definitions abroad in the literature (Alvesson and Karreman 2000). Here I will broadly follow Edwards' (1996) definition, seeing discourse as

the entire field of signifying or meaningful practices... material, institutional and linguistic, through which reality is interpreted and constructed and with which human knowledge is produced and reproduced... a background of assumptions and agreements about how reality is to be interpreted and expressed.

Kaasgard (1998) concurs, seeing discourse as embodying the "deep structure" of organizational culture, its underlying system of rationality which provides members with both an interpretative and normative framework. Whilst discourse constitutes social reality, the relationship is, of course, a reciprocal one: "discourse is both socially constituted and socially constitutive as it produces objects of knowledge, social identities and relationships between people" (Hardy et al. 2000).

The functioning of discourse as a defense against anxiety is the main topic of this paper. Two aspects of anxiety, existential and task-related, are relevant to this role. Discourse and the struggle for identity are fundamentally intertwined. Belonging to a social group (which confers a sense of self) means subscribing to its discourse; as Mumby and Chair (1997) note, discourse is "the principal means by which organizational members create a coherent social reality that frames their sense of who they are." Thomas and Linstead (2002) elegantly illustrate how middle managers attempt to construct their sense of self in an uncertain world, through participation in discourses regarding their role in the organization. In Giddens (1984) terms, discourse confers ontological security. This existential bargain is, of course, a Faustian one. If a sense of identity can be given it can also be taken away. Hence the norms of discourse exercise a subtle but highly potent disciplinary influence, via the threats of ostracism and anomie. Kinsella (1999) illustrates the exercise of this power in maintaining harmony and resolving conflict in a "Big Science" laboratory. 
Explicit coercion is seldom exercised to maintain a disciplined social order; discourse operates a hegemonic power, sanctioning certain behaviors and interpretations while excluding others. Studying social power in a setting devoted to the investigation of raw physical power (The Princeton Plasma Physics Laboratory) provides a nice irony.

Organizational discourse provides a defense against specific task-related anxieties as well as providing security in the face of existential uncertainties. In her pioneering work on nursing practices, Menzies-Lyth (1988) interprets the apparently heartless and mechanical way that nurses follow treatment protocols (i.e., their adoption of the professional discourse of nursing) as a device for containing the pain that would ensue were they to engage with their patients at a more personal level. Hirschhorn (1988) further develops the idea that an organization's social systems, sustained through discourse, represent an elaborate system of social defenses to contain task-related anxiety. Little et al. (2001) comment on how the adoption of a technical language serves to create distance between human beings (individual patients becoming generic clients) and hence diminishes the anxiety attending on direct human engagement.

Wastell $(1997,1999)$ has applied a similar analysis to help explain some of the dysfunctions of information systems development (ISD). He argues that seemingly rational behaviors, such as adherence to a methodology, at a deep level reflect underlying defensive processes. Adopting the technical discourse provided by the methodology endows both a sense of professional identity and a feeling of mastery. The methodology simplifies the complexities of ISD, conferring a kind of magical fantasy that, if its rituals are followed, this will of itself produce the information system, finessing away the difficult and painful human encounters that are all too often involved. Long (1999) contends that the hierarchies of the traditional public sector bureaucracy (the discourse of dependency) afford existential and material security (a job for life, and so on). While these certitudes are under threat from new discourses (e.g., consumerism), they too contain their own defensive structures (e.g., the resignification of complex human beings as standardized customers).

\section{ORGANIZATIONAL CHANGE FROM A DISCOURSE PERSPECTIVE}

This section will consider in greater depth the issue of organizational change from a discourse perspective. From this viewpoint, change initiatives reflect the attempt of some new discourse to establish itself within the prevailing discourse matrix of the organization. Hardy et al. (2000) view discourse as a strategic resource which can be mobilized to effect organizational transformation. They describe three phases (or circuits) whereby the proponents of change initially 
articulate new discursive statements (the circuit of activity), then progressively engage others by embedding the new concepts in a shared discursive context (the circuit of performativity); in the third circuit (of connectivity) the discourse takes as other actors adopt its concepts in a meaningful way, and new practices and subject positions (legitimated positions from which to view the world and to take action) begin to emerge.

A similar perspective is adopted here, but using actor network theory (Latour 1987) as the theoretical lens for viewing change as the adoption of new discourse. ANT provides a rich and well-established account of the "sociology of translation" whereby new "candidates for existence" (knowledge, technology, discourse) become assimilated within a given sociotechnical collective (McMaster et al. 1999). The theory has attracted much interest in the IS context as a perspective on both organizational change and technology transfer. Doorerward and van Bijsterveld (2001) and Lowe (2001) provide two recent examples. ANT's symmetrical treatment of human and nonhuman actants is particularly appealing here, as it enables agency to be ascribed to discourses independently of human actors. From an ANT standpoint, the situation regarding new discourses is analogous to that of technology transfer; ANT rejects the conventional, passive view of the latter (classical diffusion theory) instead seeing it as an active reciprocating process in which both the old and the new mutually influence each other. In a discourse context, Dooreward and van Bijsterveld use the metaphor of osmosis to convey something of the active, mutually transformatory nature of the mixing process. Their argument is that new discourses are always reinterpreted on encountering established ones. And of course these preexisting structures are themselves reshaped in the same process. The old provides the framework for understanding the new, and the attempt to understand the new in terms of the old itself changes our prior understanding of the world. The result of this dialectical process (an apt term in the present context!) is a synthesis containing elements of both original discourses, to varying degree, but which is also something new, with emergent properties of its own.

Cognitive effort is required to adopt a new discourse. The new words, concepts, and practices need to be learned, their meaning internalized and built into the individual's linguistic and behavioral repertoire. This effort alone is a deterrent to the adoption of new paradigms. Resistance from more fundamental sources is also inevitable given what we have said regarding the defensive rationale of established discourse formations; assimilating the new discourse entails some letting go of the security provided by the old. Regarding organizational change as the attempted adoption of a new discourse, we can regard the change as successful to the extent that the new discourse comes to form part of the discursive furniture of the organization. To the extent that it is held off, we would regard the change effort as having failed. The strength of the defenses 
within the incumbent discourses will play a decisive role in influencing this outcome, with stronger defenses implying greater resistance.

From a translation point of view, there are three primary steps (moments) in the progression from the appearance of something novel to its assimilation in a collective. These steps are referred to as the hierarchy of moralization (Lowe, 2000): alignment is the first (the initial drawing in of organizational actants through problematization and interressement) followed by enrolment (whereby networks of allied interests are progressively constructed) and finally there is congealment (whereby the new entity consolidates itself as a accepted fact of life, a "black box," as part of the transformed order). Latour provides trenchant insights into the range of rhetorical devices whereby networks are constructed through the enrolment of actants into stronger and stronger structures.

\section{THE DISCOURSE OF ELECTRONIC GOVERNMENT}

The substantive focus of this paper is on a relatively recent but formidable discourse, of electronic government, that is potentially far-reaching and pervasive. Huge investments are being made across the globe on the implementation of information technology (IT) systems to support governmental functions at all levels. In the UK, the new Labour government in its first term (1997-2001) put considerable emphasis on the need to modernize government, with IT seen as having a key part to play in the realization of this policy (Silcock 2001). The 1999 White Paper, Modernising Government, challenged all public sector organizations to achieve citizen-centered services by integrating policies, programs and service delivery. Three key aims were espoused: (1) to ensure that policy making is more "joined up" and strategic; (2) to ensure that public service users, not providers, are the focus by matching services more closely to peoples lives; and (3) to deliver efficient, high quality, responsive services. IT was seen as critical to achieving these aims. The White Paper committed the government to the "use of new technology to meet the needs of citizens and business and not trail behind technological development."

The White Paper addressed e-government at all levels. The present paper will be specifically concerned with local rather than central government, i.e., with city or county level democratic institutions (and supporting bureaucracy) which take responsibility for policy making and many aspects of public service delivery within their immediate locale. Local government has three general functions in most countries: to provide the mechanisms of local democracy, to be the focus for public policy making and to provide a range of public services in those social domains deemed to be better served by noncommercial, nonmarket-driven agencies. IT clearly has the potential to contribute to enhancing all three areas: local democracy (by the electronic dissemination of party 
political information, electronic voting etc.), policy making (assessing local needs, facilitating multiagency cooperation) and service delivery (e.g., 24 hours a day, 7 days a week service access via the Internet).

Ambitious targets have been set for the UK's e-government program. The Prime Minister originally pledged that by 2002, a quarter of all transactions should be capable of electronic mediation, rising to 100 percent by 2008 . In March 2000, he proclaimed, "I want the UK to be the world's leading Internet economy" (Silcock 2001) and the targets were escalated, with 2005 now stipulated as the deadline for full coverage. To facilitate these aims, substantial new funding has been allocated; in the local government arena this currently amounts to $£ 350$ million over several years. A national performance indicator has been implemented, designated BVPI157, in order to measure the progress of individual institutions toward the 2005 target (the indicator simply measures the proportion of transactions with the local authority that can be performed electronically). A so-called Pathfinder initiative was launched in 2001, whereby $£ 25$ million of new funding was set aside for those authorities able to demonstrate a leading position in relation to some aspect of e-government. All LAs were also obliged to produce Electronic Government strategies by July 2001 . The creation of a dedicated government office (the Office of the E-envoy) and initiatives such as "UK on-line" (a partnership between government and industry aimed at enabling wider access to the Internet) have also been important in propelling the e-government agenda.

E-government is manifestly a very potent discourse, one well worthy of study. It is, therefore, pertinent to question how well the discourse is actually penetrating the discursive fabric of local institutions and bringing about the sort of fundamental changes that its rhetoric of modernization so fervently espouses. This question is the substantive focus of the present paper. Empirical evidence is hard to obtain at present, although there are revealing signs that the reality and the rhetoric are somewhat out of step. The BVPI157 data available in early 2002 suggests that limited progress is being made, e.g., only 15 members of the Society of IT Managers in local government indicated that they had currently achieved the 2002 target of 50 percent coverage, i.e., only 8 percent of the Society's membership. A recent report (Filkin et al. 2001) comments that although

the e-revolution has the potential to bring about major improvements... a clear policy framework and strong leadership will be needed if these are to be realized by 2005 . There is currently no agreed vision or targets for e-government locally and most authorities do not know what they need to do. 
A former senior civil servant recently commented (BBC Sci/Tech report, 21 April 2002) that

It is rhetoric rather than reality... at the moment the government is giving citizens what it thinks they want rather than what they actually want....People like to interact face to face.

The same BBC report also notes the concern of the National Audit Office that there is "much to do" if e-government targets are to be met.

Thus far, I have adumbrated the main rhetorical features of e-government discourse in the UK and set out the lineaments of my theoretical stance in relation to the operation of discourse as a social defense and the light this throws on organizational change. In the rest of the paper, this theoretical perspective will be applied to attempt to understand the permeation of e-government discourse in one concrete setting, a local government institution in the northwest of England. To distinguish between the more abstract e-government discourse as espoused by central government and its local concrete instantiation in the field site, I will refer to the former as the global e-government discourse and the latter as the local discourse. Alvesson and Karreman (2000) distinguish four levels of discourse, ranging from microdiscourse (social text in a specific microcontext) through to mega-discourse, which embraces general universal ideas in a more or less context free way. The present notion of local discourse corresponds to the micro/meso levels of their hierarchy, and global discourse to their notion of grand discourse. The goals of the analysis are to gain some insights into the reality of e-government implementation and to evaluate the utility of the present theory by assessing how well it helps interpret the playing out of events in the field site.

\section{METHODOLOGY}

The field partner in this research will be referred to as Erewhon City Council (ECC). ECC has recently achieved national recognition for its egovernment program, in the sense that it had been designated one of the first wave of Pathfinders. Nine internal e-government projects were underway at the time of the study. Most were apparently progressing satisfactorily, although there was slippage on some. The study reported here was commissioned by the senior management team of ECC, in response to prompting by the manager of the IT department who was concerned that, despite the Pathfinder success, there was a lack of genuine "buy-in" and commitment on the user side. Not all projects were being actively led by users, and several had not moved beyond 
design work into implementation. The remit of the study was to explore $e$ government awareness at a senior level in the authority, to assess preparedness for implementation, and to propose interventions that would facilitate progress.

The study was an interview-based one, with all heads of service (directors) being interviewed (Housing, Social Services, Corporate Services, Environment, Education, Planning, Development Services, Partnerships, and Regeneration) as well as the Chief Executive. This entailed a total of 10 interviews, each with a single manager. Interviews were all face-to-face and took around one hour. They were not tape-recorded; instead detailed notes were taken, including direct quotations where these were felt to be pithy or particularly revealing. Prior to the study, a focus group session was held involving representatives of the IT department in order to generate a list of indicative questions to be put to the directors. These questions were used to compile a semi-structured interview schedule, which was circulated in advance to the interviewees.

The questions revolved around three broad areas:

- The meaning of e-government: What does e-government mean to you? Can you think of specific examples of e-government projects relevant to your directorate? What level of awareness exists among your staff with respect to e-government?

- Planning and management: What are the main features of your plans for service improvement and what role does IT play in this? Does your directorate have specific e-government plans? Do you have a senior person leading your e-government activity? What personal involvement will you have?

- Capacity and implementation: Do you feel you have sufficient internal capacity to address the e-government agenda? What shortcomings do you face and how might these be met? What are the main obstacles to egovernment being a success? How many of your transactions will be electronically enabled by $2002 / 2005$ ?

\section{RESULTS}

\subsection{The Meaning of E-Government}

The directors gave a variety of specific interpretations of e-government: new channels of service access; joined-up services across and within directorates; cost saving; quicker, streamlined services; more effective communications, internally and externally; freeing resources to concentrate on core service aims; flexibility and responsiveness of service provision. In general, these broad views 
manifested a strong service orientation; very little mention was made of either the democratic or policy making role of local government. The following quotes are typical:

For me e-government means rapid access to joined up services. I'm very committed to this....People expect a 24 hour a day service. It's all about the standard of service...we need to be as good as the private sector providers. We need to be in a position where receptionists can directly commission work even though resources are in the directorates.

E-government should be customer-focused, not technology. Central government are not really serious, it's like Wilson's white heat of technology. Just Whitehall control freakery, keeping costs down. E-government is about a new means of delivering service using computers, a 24-7 culture that's customer led.

When prompted to provide e-government exemplars, the illustrations given were almost exclusively centered around service improvement within individual departments. Exemplars included online job applications; e-learning initiatives such as induction training and renewal of qualifications; Web advertisement of planning applications; and housing repairs and estate agency functions to be put on the Web. No applications involving cross departmental collaboration were cited and only one example was given of external partnering, namely the provision of a joint occupational health service with other LAs.

Several directors questioned whether e-government was fundamentally new, identifying the long history of IT and organizational change in their departments, and suggesting that it had to be seen in that context. All directors strongly emphasized the links between e-government and current programs for service improvement, specifically the so-called "Best Value" process whereby all local authorities are obliged by central government to demonstrate (via a series of national performance indicators) that their performance provides good value for money. Two comments:

E-government is nothing new...we do it anyway.

E-government is absolutely vital to Best Value-we have to look at e-government as part of Best Value-we will fail the BV test unless we have a much enhanced IT system. 


\subsection{Planning and Management}

Only two of the directorates had specific e-government plans or were in the process of creating these plans. The others reported different ways of planning for e-government, including progressing it through a series of different initiatives or through the normal business planning process. Some saw e-government as being a corporate concern, largely addressed in current plans to set up a call center.

We have no separate e-government plan, but we need to fit within the corporate plan, we want to be part and parcel of this and work within it.

We need to rationalize and fit in with the corporate approach, to take advantage of the call center somehow. Our existing systems are disparate. We need an integrated system, this will make a vast difference to the service.

Although all directors acknowledged that e-government was a priority, with the overwhelming majority indicating that they expected to play a personal role, there was general lack of clarity as to what this would entail beyond being "facilitative." The gap between espoused commitment and actual engagement is starkly shown in the following quote:

E-government is about real communication, internally and externally, regarding what the Council is really about....I don't know though how many of my staff use email...perhaps this is a weakness of mine that I don't know.

Most departments had appointed a given individual as an e-government champion; e-envoy was the term used, adopting the rather "e-gregious" [sic] terminology of central government. However, this individual was seldom at a senior level and in some cases there was no explicit e-government champion. Most directors reported that their senior management team (SMT) had a role in reviewing and leading e-government activity, but this was generally implicit rather than explicit.

We have an IT manager but no e-government champion. He's not on the SMT but reports to someone who is. 
Different levels of staff awareness were reported. Although it was felt that staff increasingly thought about the general relevance of IT, the idea of egovernment as such was not felt to be widely appreciated.

People think about IT in it's broadest sense. We have the technology, how can we use it. But they're not really thinking egovernment.

\subsection{Capacity and Implementation}

Five directors identified resource issues as presenting a key obstacle to egovernment. They described difficulty with capital investment and pressures from alternative priorities and needs. Other obstacles included change resistance, lack of awareness or appreciation, legacy systems, and problems of delivering complex IT solutions on time and to budget. All directors reported that there were issues with capacity. Two commented directly on the need to strengthen their IT teams. There were some positive comments on the lines that "awareness creates capacity" and that many problems could be put down to poor planning and lack of preparedness.

Despite these prevalent concerns, five directors were bullish that the 2005 e-government targets would be met.

There's no alternative...we just have to do it. By 2002, we'll have done a lot ... by 2005 everything.

Capacity is constantly a problem with the Council but we have to manage... if we use capacity as an excuse we'll never achieve anything...can't accept $N O$ as an answer.

Others were more realistic. Many commented that they did not have ready access to information about what transactions were already supported or would be supported in the future. The following quote indicates something of an extreme position regarding the director's real commitment to achieving the 2005 targets:

I haven't really thought about this... I would be fibbing if I said I had! 


\section{DISCUSSION}

Let us begin this final section by summarizing what seem to be the main themes characterizing the reality of e-government discourse in the field setting. The most prominent feature emerging from the interviews is the preoccupation with internal service improvement, rather than integration with other directorates (or external partners) or other potential aspects of the e-government agenda (policy making, e-democracy). There is little sense from the microdiscourse that e-government is really seen as anything new or radical; it has seemingly, for the moment at least, been translated into old and familiar issues, namely the ongoing need for professional providers, operating largely within their own prerogative and perception of the world, to review and enhance service delivery. This sense of psychological distancing comes over in other ways: the dearth of departmental e-government planning, the view that e-government was largely a corporate issue, the paucity of joint ventures despite the injunctions in the global discourse to join-up services, the lack of real personal engagement, the plaintive comments regarding resources. The unrealistic optimism that targets can be realized without clear plans, departmental engagement and adequate resources suggests a comforting fantasy based on denial rather than genuine conviction.

How may we understand these discourse patterns in terms of the defensive structures operating in ECC? Long (1999) characterizes the traditional discourse of public sector organizations as a discourse of dependency, with services being seen as the prerogative of a professional elite who define what the community needs and take largely unilateral control over planning and delivery. The professionals "know best" what the community needs and the community gets what it is given. This discourse is profoundly defensive. Externally, it minimizes interaction between professional providers and the local community (even via elected members who, while theoretically the decision makers, are all too often marginalized by officials). Interaction with the community is problematic for bureaucrats as it means confronting a real world that is complex, potentially uncompliant, and demanding of accountability. Building a psychological boundary around the service department thus minimizes task-related uncertainties. The bureaucratic method of organizing is itself a social defense, as was noted in the Introduction; its rituals enable individuals to abrogate personal responsibility and avoid genuine human engagement. The adoption of a professional discourse also allays existential uncertainty by affording a strong sense of role and self.

The discourse of dependency has been under constant threat in recent years, in all areas of the public sector including health (Lowe 2000, 2001). Long encapsulates these developments as the advent of a discourse of consumerism. Its main organizing concepts are the sovereignty of the customer and the need 
to reframe business practices on the principles of the market economy. The Best Value imperative in the UK (Wilson and Game 1998) finely exemplifies the new discourse, with its insistent stress on measurement, customer satisfaction, and the overwhelming drive to be competitive. The imperative to modernize is integral to the new rhetoric; the old is necessarily seen as bad with the pejorative implication that any resistance or attempt to uphold the traditional is retrograde.

By emphasizing the need to embrace externalities and to reorganize around the needs of the customer rather than the professional discipline, the discourse of consumerism is profoundly threatening to the defense structures embodied in the traditional discourse of dependency (Long 1999). The global discourse of e-government poses similar threats as it contains many of the elements of the discourse of consumerism; it is, if anything, more minatory in its explicit championing of joined-up service planning and delivery across disciplines, notions which directly threaten the professional empires. Such joint ventures are deeply problematic from a psychodynamic perspective, as Gould et al. (1999) have shown. Any partnership requires commitment and sharing, but this brings the risk of dependency, raising paranoid anxieties revolving around issues of trust. Gould et al. describe the failure of a commercial joint venture which arose from fears of inequity in the sharing of knowledge and capability. Fearful of the risk of mutual dependency, the partners held back; while espousing the rhetoric of togetherness and acting out the rituals of collaboration, in reality they risked little, and maintained a readiness to walk away throughout.

From the present perspective, organizational change is seen as a process of translation in which a new discourse confronts established discursive structures, engaging in a kind of "trial of strength" (McMaster et al. 1997). The change is successful to the extent that there is genuine discursive transformation, betokened by the congealment of new practices, cognitive schemata, social relations and subject positions. Despite its position as an e-government Pathfinder, analysis of the discourse in ECC indicates that such a radical conversion has not yet transpired. We see in the local discourse how the imperatives and claims of the global discourse have largely been repelled. Alignment is little more than lip service, and there is scant evidence of genuine enrolment. The threats posed to the established social defenses appear to have evoked a powerful but subtle form of resistance, reflected in the deployment of a range of devices to deflect and neutralize the more threatening elements of the global discourse. Certain elements of the latter are simply not heard (the defense of denial); others are translated into activities that are familiar and unthreatening, i.e., an internally contained debate regarding service improvement rather than an externally oriented discourse regarding the needs of the community, new service options, and the necessity of cooperation with other agencies. Further elements of the consumeristic rhetoric are simply split off and projected onto 
corporate developments such as the call center, as if to say that responsibility for customers is no longer our concern (i.e., the directorate's) -it's the job of the call center. Ironically, this device will strengthen the existing boundary between departments and the community.

In a further twist, BVPI157 itself provides another defensive translation. This performance indicator essentially operationalizes e-government as the need to provide Internet access to services. Through two tropes, first the translation of e-government into an issue of access and then translating this into Internetbased access, e-government becomes merely a question of a new interaction channel. This translation resonates with other aspects of the social defense structure of ECC, relating to the relationship of the IT department vis-à-vis the service departments. The situation of IT is an invidious one (Pratchett 1999): clearly, the department has a key role in the modernization agenda, but as a support function it is always in a weak and dependent position, unable step outside the established discourse norms which emphasize service provision or to act as a change agent without the full cooperation of the service providers. The translation of e-government into BVPI157 thus provides a welcome relief to IT as well as to the service departments. It provides the former with a tractable role (of providing Web-based interfaces to existing systems) minimizing the problematic need to engage with departments at a deep level. The service providers also have a lot to gain from this defense, as they can escape the rigorous scrutiny that fundamental reengineering might entail. Hence the translation of e-government into BVPI157 is supported by a collusive alliance of both IT and the service departments. Hirschhorn (1988) refers to this form of defense as a "covert coalition."

The aims of the present study were to evaluate the reality of e-government implementation as well as the relevance and utility of the discourse perspective as a theoretical device for understanding organizational change. Regarding the former, it is clearly disturbing for the champions of modernization to find such a degree of apparent resistance, especially in a Pathfinder. This suggests that the national situation, as represented in the published statistics, is overly sanguine if e-government is to be taken seriously as fundamental transformation rather than superficial changes in methods of access. Regarding the theoretical value of the discourse perspective, the insights provided by the present analysis amply confirm its efficacy. Although the focus has been on defensive translations, discourse analysis can also be used in a more critical way to look beneath rhetorical facades and bring out the underlying ideologies that provide political motivation. Pearson (2000) for instance, contrasts the microdiscourses of two local authorities in relation to direct welfare payments, focusing on the tensions between two grand discourse strands (the market and social justice) and how uneasily these sit alongside one another while both superficially supporting the 
idea of direct payment. The tendency of one or the other to prevail is traced back to the very different political traditions in the two authorities. On a grander scale, Crow and Longford (2000) deliver a trenchant exposé of the pro-capital, neo-liberal agenda underlying the utopian hyperbole so characteristic of information society rhetoric. Who benefits most from e-government we might well ask? Certainly the IT industry is a clear winner.

To see discourse as a strategic resource for organizational transformation is hardly a novel insight; the very essence of rhetoric is to change the world. The key question is to understand how discourse brings about such reconstruction, or not as the case may be: "how thinking up, or to be more precise talking up, a new strategy translates into organizational actions... how can an organization transform itself simply thinking up a new strategy" (Hardy et al. 2000). Of course, it can't. That is the message of the present work. Theory is needed to help unravel the processes of discourse translation that are involved. In this paper, we have seen how the enrichment of the discourse perspective with concepts from the sociology of translation and psychodynamic theory provides a powerful framework for understanding the processes of organizational transformation and resistance. We have seen how the social defenses in ECC have in effect arrested the translation process at the first moment, that of problematization. The claims raised by the new discourse have simply been ignored or deflected, assimilated one way or another into preexisting concepts and practices rather than congealing into a genuinely novel discourse. Of course, this study itself is part of the translation process. It can be seen as an attempt to reproblematize the notion of e-government in ECC, in order to give fresh impetus to the global discourse, which was perceived by some key actants to have become sidelined. The global discourse is a powerful one, with many elements that are of real potential benefit. It is unlikely that its claims can be resisted permanently and it is important for ECC to engage more wholeheartedly if the socially corrosive side effects of e-government (e.g., exacerbating the digital divide; Keeble and Loader 2001) are to be avoided and the positive elements of egovernment discourse to be critically drawn out and translated into practical policies.

\section{REFERENCES}

Alvesson, M., and Karreman, D. "Varieties of Discourse: On the Study of Organizations Through Discourse Analysis," Human Relations (53), 2000, pp. 1125-1149.

Crow, B., and Longford, G. "Digital Restructuring: Gender, Class and Citizenship in the Information Society in Canada," Citizenship Studies (4), 2000, pp. 207-230.

Doorewaard, H., and van Bijsterveld, M. "The Osmosis of Ideas: An Analysis of the Integrated Approach to IT Management from a Translation Theory Perspective," Organization (8), 2001), pp. 55-76. 
Edwards, P. N. The Closed World: Computers and the Politics of Discourse in Cold War America. Cambridge, MA: MIT Press, 1996.

Filkin, G., Dempsey, S., Larner, A., and Wilkinson, G. Winning the E-Revolution in Local Government. Layerthorpe, England: York Publishing Services, 2001.

Giddens, A. The Constitution of Society. Cambridge, England: Polity Press, 1984.

Gould, L. J., Ebers, R., and Clinchy, R. M. "The Systems Psychodynamics of a Joint Venture: Anxiety, Social Defenses and the Management of Mutual Dependence," Human Relations (52), 1999, pp. 697-722.

Hardy, C. Palmer, I., and Phillips, N. "Discourse as a Strategic Resource," Human Relations (53), 2000, pp. 1227-1248.

Hirschhorn L. The Workplace Within: The Psychodynamics of Organizational Life. Boston: MIT Press, 1988.

Kaasgard, K. "The Value of Discourse Analysis in Understanding Cycles of Redesign of IT in Organizations," in Third International Conference on Organizational Discourse: Pretexts, Subtexts and Contexts, London, 1998.

Keeble L., and Loader B. Community Informatics: Shaping Computer-Mediated Social Relations. New York: Routledge, 2001.

Kinsella, W. J. "Discourse, Power and Knowledge in the Management of 'Big Science,," Management Communication Quarterly (13), 1999, pp. 171-208.

Latour, B. Science in Action. Boston: Harvard University Press, 1987.

Little, J., Blackman, P., and Rouham, J. "Social Policy and Humanity: The Use of Language as a Defense Against Anxiety," Australasian Psychiatry (9), 2001.

Long, S. "The Tyranny of the Customer and the Cost of Consumerism: An Analysis Using Systems and Psychoanalytic Approaches to Groups and Society," Human Relations (52), 1999 , pp. 723-743.

Lowe, A. "Accounting Information Systems as Knowledge-Objects: Some Effects of Objectualization," Management Accounting Research (12), 2001, pp. 75-100.

Lowe, A. "The Construction of a Network at Health Waikato," Journal of Management in Medicine (14), 2000, pp. 210-239.

McMaster, T, Vidgen, R., and Wastell, D. "Technology Transfer: Diffusion or Translation," in T. McMaster, E. Mumford, E. B. Swanson, B. Warboys, and D. Wastell (eds.), Facilitating Technology Transfer Through Partnership: Learning from Practice and Research. London: Chapman \& Hall, 1997, pp. 64-75.

McMaster, T., Vidgen, R., and Wastell, D. G. "Information Systems Development and 'Due Process': The Case of the Van Sant Map," in T. J. Larsen, L. Levine, and J. I. DeGross (eds.), Information Systems: Current Issues and Future Challenges. Laxenburg, Austria: IFIP Press, 1999.

Menzies-Lyth I. Containing Anxiety in Institutions: Selected Essays. London: Free Association Books, 1988.

Mumby, D. K., and Chair, R. "Organisational Discourse," in T. A. van Dijk (ed.), Discourse and Structure and Process, Volume 2. London: Sage, 1997.

Pearson, C. "Money Talks? Competing Discourses in the Implementation of Direct Payments," Critical Social Policy (65), 2000, pp. 459-477.

Pratchett, L. "New Technologies and the Modernisation of Local Government, " Public Administration (77), 1999, pp. 731-750.

Silcock, R. "What Is E-Government?”, Parliamentary Affairs (54), 2001, pp. 88-101.

Thomas, R., and Linstead, A. "Losing the Plot? Middle Managers and Identity," Organization (9), 2002, pp. 71-93.

Wastell, D. G. "Learning Dysfunctions in Information Systems Development: Overcoming the Social Defenses with Transitional Objects," MIS Quarterly (23:4), December 1999, pp. 581600. 
Wastell, D. "The Fetish of Technique: Methodology as a Social Defense," Information Systems Journal (6), 1996, pp. 25-40.

Wilson, D., and Game, C. Local Government in the United Kingdom. Basingstoke, England: Macmillan, 1998.

\begin{abstract}
About the Author
David Wastell earned his Ph.D. in Psychology from the University of Durham in 1978. He then moved to the Applied Psychology Unit in Cambridge where he undertook a major project involving the psychophysiological analysis of technological change in British Telecomm. In 1980, he moved to Manchester taking up a lectureship in Medical Informatics. He was promoted to Senior Lecturer in Information Systems in 1990, and in July 2000 took up his present position as Professor of the Information Society at the University of Salford, a new Chair partly financed by the City of Salford. David has extensive research interests in the field of Information Systems. His main interests are in electronic government, knowledge management, business process reengineering, IS methodology, and the cognitive engineering of complex systems. David also has considerable practical experience in IS development, gained as a practitioner and a consultant, in both the private and the public sectors. David can be reached by e-mail at D.Wastell@salford.ac.uk.
\end{abstract}

